\begin{tabular}{lllllll}
\hline REVISTA IBEROAMERICANA. & Vol. LXII, Núm. & 174, & Enero-Marzo & $1996 ;$ & $85-102$ \\
\hline
\end{tabular}

\title{
EDICIÓN PRÍNCIPE DE LA NOVELA OLIMPIO PITANGO DE MONALIA (1915) DE EDUARDO L. HOLMBERG: TEXTUALIZACIÓN DE LA MODERNIDAD ARGENTINA
}

\author{
POR \\ GIOCONDA MARúN \\ Fordham University
}

La edición príncipe de Olimpio Pitango de Monalia (1915) de Eduardo L. Holmberg, se hizo sobre el manuscrito autógrafo del texto nunca publicado. ${ }^{1}$ El 22 de junio de 1927, al cumplir Holmberg 75 años, el periódico La Razón le hace un reportaje. Refiriéndose a Olimpio Pitango de Monalia Holmberg expresa:

\begin{abstract}
De todo lo que he escrito, esto es lo que más quiero. Hace diez le puse punto final, y no lo he vuelto a tocar, más que para releerlo en mis ratos perdidos. Sin duda no he de publicarlo nunca ...2
\end{abstract}

La novela es una descripción de una isla imaginaria, Monalia, en donde en 1912 un sabio escritor, Olimpio Pitango, especie de héroe épico, provoca una verdadera revolución al exponer la necesidad de que su país se organice constitucionalmente para que pueda entrar en el concierto de las naciones más civilizadas, entre las que estaba la Argentina. Su plan de reforma tiende a que la nación tenga héroes, ruinas históricas, partidos políticos, constitución, todo lo que tenían los países más avanzados y de que Monalia carecía hasta ese momento. Así fantásticamente se crea una situación falsa, se descubren ruinas históricas, se inventan héroes. La locura de Olimpio Pitango trasciende y la reacción de los países europeos ante este nuevo Don Quijote, inunda Monalia de burlas feroces e ironías. Lo extraño de la situación obliga al gobierno de Monalia a alejarlo del medio. Olimpio es enviado como ministro plenipotenciario a Sud América, pues aquí encontraría todo lo que él había estado buscando para Monalia. Pero las cartas y reflexiones de Olimpio sobre la Argentina y las demás naciones sudamericanas van ilumimando un cerebro sagaz. El gobierno de Monalia comprende finalmente que Olimpio no está loco, cuando él les revela que debió exponer los fundamentos de la reforma "en una forma fantástica y descabellada para una minoría seria y grave ... pero imponente y necesaria para una mayoría abrumadora"

\footnotetext{
' Gioconda Marún, ed. Olimpio Pitango de Monalia de Eduardo L. Holmberg(Buenos Aires: Dimensión Argentina, Solar, 1994). Edición realizada con el auspicio de The Organization of American States (OEA), Washington.

2 "Cumple 75 años en estos días el doctor Eduardo L. Holmberg, prototipo del sabio y del maestro en la Argentina. Una biografia a grandes rasgos, algunos recuerdos y una revelación: en breve publicará su último libro, obra maestra de humorismo, de ironía y de interés" (La Razón, 22 de junio de 1927, col. 3-5, s.p.).
} 
(164). Su plan de reforma surgió ante la expansión territorial de las naciones capitalistas y las aspiraciones de la alta Banca. Olimpio Pitango previó el peligro de los deseos expansionistas de las grandes potencias; su obra fue una visión de futuridad y así lo pudo entender finalmente el gobierno que lo convirtió en héroe nacional.

A través de XVI capítulos se va describiendo la transformación política operada en la isla de Monalia, "paraíso terrenal" no sólo por su clima y vegetación, sino por el ejercicio de la libertad espontánea entre los ciudadanos y la práctica de una democracia perfecta. Monalia sufre el proceso de modernización con todas sus consecuencias, y en este despertar político, va reflejando lo sucedido a las naciones sudamericanas, después de la independencia de España. ${ }^{3}$

\section{VISIÓN CARNAVALESCA DE UN MUNDO AL REVÉS}

Por la asombrosa libertad del argumento y por el universalismo filosófico presente, que contempla el mundo dentro de una visión carnavalesca, la novela es una sátira menipea según la define y estudia Bakhtin. ${ }^{4}$ La sátira menipea fue el género más propicio para la recepción de elementos derivados del carnaval, aparentemente heterogéneos e incompatibles: ideología filosófica y ética, países imaginarios, aventuras fantásticas, violación de normas y de etiquetas, multiplicidad de géneros y de discursos. Elementos estrechamente integrados en un principio unificador: el sentido carnavalesco del mundo.

Olimpio Pitango es el héroe que encarna la invención temática: la necesidad de que Monalia tenga historia, se organice constitucionalmente. Esta idea origina las más disparatadas circunstancias por medio de las cuales el héroe pierde su unidad épica al ser tildado de loco, para luego recuperarla bruscamente después de su sabia actuación en los países extranjeros. Contribuyen a esta visión carnavalesca característica de la sátira menipea las situaciones extremas y ridículas presentes en la novela, las distintas interpretaciones paleográficas, la invención de héroes y de documentos históricos, la pluralidad de discursos opuestos y la multiplicidad de géneros. Tono múltiple y dispar, integrado como en el carnaval, para crear la representación de un mundo al revés, el de la civilización actual.

Es posible seguir en Olimpio Pitango de Monalia los caracteres definitorios de la sátira menipea elucidados por Bakhtin, ${ }^{5}$ que procederé a puntualizar.

Un epígrafe en francés encabeza la primera página del manuscrito firmado por L. K., iniciales aclaradas al final de la página, cuando después de un comentario que sigue al epígrafe, firma Ladislao Kaulitz, uno de los seudónimos de Holmberg. ${ }^{6}$ Es importante

\footnotetext{
${ }^{3}$ La novela, aunque se desarrolla en una isla imaginaria, Monalia, no es una utopía pues este paraíso terrenal se destruye por imitar a las naciones más civilizadas. Como demostraré en mi estudio de la obra, Monalia es el microcosmos de otro mundo al revés, el de la civilización actual.

${ }^{4}$ Los efectos que las festividades y ritos del carnaval tuvieron sobre la literatura constituyen para Bakhtin la carnavalización literaria (M. M. Bakhtin, Problems of Dostoevsky's Poetics [Minnesota: University of Minessota, 1984]).

${ }^{5}$ Bakhtin, op. cit., 114-134.

${ }^{6}$ En realidad Holmberg ha usado en otras publicaciones el nombre Ladislao Kaillitz. En Dos partidos en lucha (1875), él se incluye como personaje de la obra con este nombre. Ladislao Kaillitz es el
} 
detenerme en esta página, sin enumerar, por su significado interno. El epígrafe en francés reza:

On vend l'immeuble connu sous le nom de Paradis terrestre avec ses lions. On a fait courir le bruit qu'un des chiens a disparu pendant la nuit dernière, mangé peut-être par un des vieux lions. C'est inexact. Le chien est caché dans un trou de la véranda, pour soigner la petite fille qui va y dormir ce soir comme un garantie de l'inexpérience des lions pour toutes espéces de chairs. Ils ne mangent que du riz. L. K. (73)

La primera idea presente aquí es la de caos y desorientación que invade el "paraíso terrestre". En la novela, Monalia, "paraíso terrestre" que vive "la paz de la edad de oro" (83), pierde, con el despertar político-institucional, todos los beneficios experimentados hasta ese momento: la justicia, el orden, el bienestar, la felicidad, el respeto de las naciones (104). Por otro lado, este proceso es además un reflejo de otros similares vividos por las naciones sudamericanas ante los deseos expansionistas de las naciones extranjeras, "los leones" que pretenden comer sólo "arroz". Por lo tanto Monalia representa el microcosmos de otro mundo al revés, el macrocosmos mundial que en esos momentos vive la iniciación de la Primera Guerra Mundial (1914-15), en la que otros "leones", las potencias extranjeras, tampoco se alimentan sólo de "arroz". Olimpio Pitango alude a esto en el texto, cuando justifica su modo de actuar ante su gobierno:

Era necesario que Monalia fuese apta igualmente como nación, ya que lo eran todos sus ciudadanos. Él no tenía confianza en la buena fe de los leones sino cuando los leones carecen de colmillos y de garras, que es cuando no sirven para nada (169).

Valiéndose de una multiplicidad ideológica y genérica, la novela desarrolla un universalismo filosófico que completa la visión carnavalesca del mundo. Ruptura del orden establecido, lograda a través de la incorporación de elementos dispares y opuestos, como se observa en el párrafo que sigue al epígrafe francés:

Cuando Goethe experimentaba la necesidad de escribir, no siempre encontraba a mano una cantidad homogénea de papel, y se valía de sobres, reversos de cartas y aún de hojas de envoltorio.

seudónimo de sus obras: "La ciudad imaginaria", La Crónica (abril 14 1884), "Filigranas de cera", La Crónica (abril 7 1884). En "El tipo más original”, El Album del Hogar, (julio 21 1878), Ladislao Kaillitz es uno de los personajes. Llama la atención que en Olimpio Pitango de Monalia utiliza la forma Kaulitz, que se repite contemporáneamente, en 1913, en "Un fantasma", La Cruz del Sur (noviembre 1913), en este relato, que proporciona importante información acerca de su niñez, Holmberg habla de su "apellido eslavo Kaulitz" y cómo "la terminación "itz' lo tuvo "mucho tiempo intrigado" (327). Según Luis Holmberg, el abuelo de Holmberg fue Eduardo Kannitz, barón de Holmberg, quien actuó en las guerras de la Independencia argentina. El apellido apareció indistintamente escrito en el medio argentino, Kanitz, Kaunitz, Kammitz, Kaillitz e incluso Kaulitz (Luis Holmberg, Holmberg. El artillero [Buenos Aires: Francisco A. Colombo, 1946]31). Holmberg, en sus obras, no está haciendo nada más que repetir las distintas versiones que circulaban de su apellido Kannitz. 
En esa misma época, predominaba el papel de hilo con más o menos rayas de aguas, que también se usaba en las imprentas, y que más de una vez, utilizando libros impresos, se han pitado los lectores a falta de chalitas.

En el momento actual nos sobra el papel homogéneo. Lo que nos hace falta son los hombres que piensan como Goethe.

Lector: elige entre el papel y el pensamiento.

Ladislao Kaulitz (73).

Este párrafo, que concluye la primera página, anticipa la doble visión que Holmberg ofrecerá en la obra: la necesidad de unidad de los países hispanoamericanos ante el imperialismo extranjero no cancela la diversidad cultural, sino que por el contrario está proclamando que la unidad de Hispanoamérica reside precisamente en su variedad. Pluralidad cultural, producto de la fusión de lo indígena y lo nacional con lo extranjero, que se manifiesta en un discurso heteroglótico. Heteroglosia que asienta la convivencia de indigenismos, de hablas rurales, regionales, de distintas normas sociales.

En el párrafo arriba citado, los americanismos pitado (pitar, fumar) y chalitas (chala del quichua challa, hoja que recubre la mazorca del maíz), están exaltando la pluralidad lingüística de Hispanoamérica y al mismo tiempo destruyendo la separación entre dos códigos lingüísticos que funcionaron en el siglo XIX separados: el de la cultura culta y el de la popular.

Por los contenidos descifrados, esta primera página funciona como metáfora de la novela, al apuntar a significados claves presentes a lo largo de la misma.

Usando los conceptos de Bakhtin, distinguiré en la novela la heteroglosia en el lenguaje, la multiplicidad de géneros y de ideas. Elementos que permiten ubicar la obra en los orígenes de la vanguardia hispanoamericana, no sólo por la visión quebrantada de un mundo al revés, el de la civilización actual, sino por la conciencia de la coexistencia de una pluralidad de voces y de culturas en Hispanomérica. ${ }^{7}$

\section{Heteroglosia EN EL LENGUAJE}

La heteroglosia ${ }^{8}$ en el lenguaje se manifiesta no sólo en la incorporación en el discurso de las voces de distinto nivel cultural registradas ya arriba, sino en la inserción de lenguas extranjeras que dialogan al unísono con los indigenismos y populismos. Las lenguas extranjeras presentes son el latín, el francés y el inglés. El libro se abre con el epígrafe en francés ya comentado. Algunas de las citas en latín, como "Si vis pacem para bellum" (156) y "In hoc signo vinces" (115) forman parte del acervo cultural. Otras como "ad referendum" (166) y "laurorum genitrix" (147), son latinismos aceptados por la norma culta e integrados

\footnotetext{
${ }^{7}$ Apud Ana María Barrenechea, "El español de América en la literatura del siglo XX a la luz de las teorías de Bajtin", Actas del II Congreso Internacional sobre el español de América. Ed. José G. Moreno de Alba (México: Facultad de Filosofia y Letras, 1986) 11-21.

${ }^{8}$ Sobre el concepto de hetroglosia, véase M. M. Bakhtin, The Dialogic Imagination (Austin \& London: University of Texas Press, 1981), 263 y sgtes.
} 
al discurso. A veces se intercala "un latinajo" o un "latín de cocina" (143), como sucede con la interpretación en latín que recibió el recorte de papel encontrado por el paleógrafo Ñanga Pichanga, que analizo en el apartado siguiente.

De las tres lenguas, el inglés es la menos frecuente, aunque Holmberg la usaba mucho pues había traducido varias obras del inglés. ${ }^{9}$ El inglés está marcando el discurso con los vocablos "market", "lectures", "starting" (97) y la expresión "They say so, but they don't mean it" (161).

Algunas veces el discurso registra los extranjerismos que ya han adquirido carta de ciudadanía, como la palabra francesa "claquer" (97) y la expresión "pour la galerie" (176), que se usa todavía en la lengua coloquial del porteño y alude a aquellas cosas que se hacen para engañar o halagar a alguien.

La heteroglosia del lenguaje señala otras veces la ruptura de las normas sociales del discurso, esta vez con el cuento final "La princesa Rayo de Luz" (cap. XVI). Este cuento maravilloso, que tiene lugar en la corte de un poderoso rey, destruye la separación entre la norma culta —el habla de los reyes, reinas-y la norma popular —el habla del pueblo. Aquí el rey, que bebe mucho durante las ceremonias reales, ante las reconvenciones de la reina repite vulgarmente más de una vez, "Al diablo el ceremonial” y juzga al Hada Madrina una "bellaca" (188).

La ruptura entre los distintos niveles de la lengua se da también en los nombres de los personajes del cuento. El trovador, que resulta ser el Príncipe Rayo de Sol, opina que la princesa que se llama Diamela, tiene "un nombre muy vulgar, el mismo nombre de una perrita lanuda de su tía Petrona" (187). La ironía es doble no sólo por la incorporación de otro nombre vulgar Petrona, sino porque Diamela, etimológicamnete viene del latín vulgar (lat. dies: día). ${ }^{10}$ Evidentemente, los conocimientos lingüísticos de Holmberg le permiten no sólo delinear una conciencia idiomática, que está marcando los dos niveles de lengua, el culto y el popular, sino jugar con la etimología de los nombres, aspecto ya desarrollado en obras anteriores.

Toda la novela es un muestrario de nombres con doble etimología, así el nombre del protagonista principal, Olimpio Pitango de Monalia. Olimpio alude a la mitología griega, el monte Olimpo sede de los dioses, Pitango viene de pitanga, argentinismo que designa al arrayán, " y Monalia, el nombre de la isla imaginaria, es el país de los monos —etimología dada por Holmberg - porque imitaron todo lo que las otras naciones hispanoamericanas habían hecho antes. Este nombre es otro hito importante que refuerza el sentido de toda la obra: la unidad en la diversidad cultural de Hispanoamérica. Hispanoamérica y especialmente la Argentina, el Uruguay y el Paraguay, las naciones con las cuales Monalia, por intermedio de Olimpio Pitango, quiere firmar un tratado de paz y cooperación, son un ejemplo vivo de

\footnotetext{
${ }^{9}$ Entre sus traducciones, Los documentos del Club Pickwick de Dickens en El Argentino 1874, El mundo perdido de Conan Doyle en Fray Mocho (Pagés La- rraya, "Estudio Preliminar", Cuentos fantásticos. De E. L. Holmberg. Ed. Antonio Pagés Larraya (Buenos Aires: Librería Hachette, 1957) 50.

${ }^{10}$ Joan Corominas, Diccionario crítico-etimológico castellano e hispanoamericano (Madrid: Gredos, 1980), s.v.

"Lisandro Segovia, Diccionario de argentinismos, neologismos y barbarismos (Buenos Aires: Coni, 1911), s.v.
} 
esa diversidad cultural que une lenguas indígenas —el guaraní y el quichua- lenguas nacionales y populares - la gauchesca - con las diversas lenguas de las sucesivas corrientes inmigratorias, que empezaron a llegar a partir de la segunda mitad del siglo XIX.

Este otro estrato lingüístico, el de los dialectos y jergas de los inmigrantes, también es registrado en el texto a través de los dos grupos inmigratorios más importantes de la Argentina, el de los andaluces y el de los italianos. Ambos discursos son transcriptos fonéticamente, el de los andaluces representado en el cuento del sevillano que no pudo llegar a Grecia, porque: “Cá; impozible; ar yegá al Estrecho del Gibrartá no' zemo encontrao una bayena atravezá que no nos dejó pazá" (116). El dialecto de los italianos aparece en el genovés enriquecido en la Argentina por la fabricación de vinos falsos: “-Ma, il vin si prepara de cuarque cosa, de cuarque cosa ... anque al úrtimo con l'uva”(156). Nueva ruptura de la separación entre la norma culta y la popular, al incorporar estos dos discursos, el del italiano y el del andaluz, pertenecientes al nivel popular de la lengua, que coexisten con el francés y el inglés, éstos dentro del nivel culto.

La Argentina es el producto de este mosaico de lenguas que detecta las distintas tensiones de las tendencias discursivas de la época, registradas tempranamente en la literatura en Olimpio Pitango de Monalia. Quizás éste sea uno de los tantos aciertos de la obra, el haber tenido conciencia de la heteroglosia de la Argentina, no sólo por su condición de nación mestiza, sino también por el carácter cosmopolita de su lengua nacional marcada por los distintos grupos inmigratorios que la poblaron.

Evidentemente Holmberg, que alcanzó a comprender "el conflicto de la lengua", como él mismo lo definió, ${ }^{12}$ estaba en una posición de privilegio para reproducir en la novela la heteroglosia del discurso de su época, no sólo por su formación científica y el conocimiento de varias lenguas, sino por sus estudios de filología y de la literatura universal.

\section{MULTIPLICIDAD DE GÉNEROS}

La polifonía y el dialogismo alternan en la obra con una multiplicidad de géneros. Junto al canónico lírico, Holmberg utiliza los siguientes géneros discursivos: el histórico, el retórico y el literario.

1. Género histórico: aparece como género serio-cómico en las interpretaciones del pliego de papel encontrado por el paleógrafo Ñanga Pichanga. El propósito es hacer una parodia de las interpretaciones paleográficas para evidenciar la falibilidad de las mismas.

Las interpretaciones paleográficas del obliterado documento acerca de una supuesta ruina histórica, dan lugar a las afirmaciones más disparatadas. Fue el "sabio" Ñanga Pichanga, el primero que reconstruye el documento "a los pocos minutos de haberlo recibido":

Es bastante fácil determinar desde la cumbre mirando hacia abajo $y$ casi $j u$ sto hacia el NO las ruinas por donde hoy pasan dos sendas y se descubren a veces algo veladas por arena de la playa, cubierta de conchillas. Se ven bien alineadas desde las montañas (140).

\footnotetext{
12 "Lo que vale una Y" (El Nacional, setiembre 1 1887, 3a-4a col.).
} 
El periódico El Regulador da dos intepretaciones más:

Se ha podido determinar apoyándose sobre base tan segura y aún ajustada hasta que punto se arruinará en salud y pensando siempre de un modo descabellado. Desduidadas las precauciones desmaya su ánimo y continúa en demencia al tenerlas por patrañas (141).

La segunda interpretación, esta vez en latín, es la "opinión de [otro] Pichanga":

Sub-hoc nomine determinare possumus crebrem punctatum orthorhynchum $j u$ dicatumm habitu sectiones gruinarum atque forsan adhuc non descriptum. Alterum ad kalendas Julius in montibus Himalaya repertum satis est conforme et fert apud hispanos nomen "alcarabán de las montañas" (143). ${ }^{13}$

Con esta interpretación en latín "de cocina", que parece ser la "nota fugaz de algún naturalista" (143), se parodia además el uso del latín en los tratados de las ciencias naturales. La ironía se acentúa cuando el periódico aconseja que se busque en el Museo de Molenia, "entre las zancudas, y en la sección de las grullas (gruinae) la que tenga el plumaje 'densamente puntuado'" (143), aquí se traduce grullas, por gruinae, en vez de gruis.

Finalmente "la interpretación del rompecabezas" se esclarece. El documento era "una tira de papel colocada como indicador en cierta foja" de un legajo, y "representaba el fragmento de un borrador de un informe médico-legal", cuyo texto íntegro, que estaba precisamente en la página indicada por la tira, era:

Es muy difícil determinar como un hombre tan rico $y \tan j u$ icioso haya podido caer en ruina. Los unos piensan que sus facultades se encontraban alteradas; los otros opinan que haya quizá confiado demasisado en alguna persona de malas mañas (144).

Aunque se menciona en el texto que cuando se anunció el descubrimiento de la hoja de papel se dio un "facsímil fotográfico" de la misma, esto no ocurre, con lo que se oscurece más el galimatías. Son las sílabas subrayadas en todas las versiones las que dan la clave de las originales "afirmaciones obliteradas" aparecidas en la hoja de papel:

determinar bre ny ju ha ruina san des das aya con en al las añas.

El propósito en todas estas versiones ha sido mostrar los extremos en que puede caer la paleografia en su afán de interpretar los documentos del pasado. La ironía se acentúa cuando se acota:

${ }^{13}$ Esta frase cuya traducción sería: "Con este nombre podemos designar al común (abundante) orthorhynchum (de pico o morro derecho) y plumaje "densamente puntuado" [que se cree que se encuentra o vive en los lugares de las grúas], y que probablemente todavía no ha sido descrito. El otro o el segundo, encontrado el 1 de julio en el Himalaya, es muy semejante y lleva en espanol el nombre de 'alcarabán de las montañas'." La frase que está entre corchete "judicatum habitu sectiones gruinarum", correspondería a un "latín de cocina" al que se alude luego en el texto. Traducción basada en la interpretación dada por el autor en la novela. 
La paleografía estállena de abrojos y bastará que recordemos cuántos comentarios arrancó a los arqueólogos, filólogos y lingüistas la interpretación de las palabras inscriptas en cierto vaso: Itis Apis Potan Dabi Cone (141).

Sátira que termina con otra humorada, pues la última frase en latín, tal como está, carece de sentido.

2. Géneros retóricos. Los géneros retóricos satirizados son la arenga y las diatribas o polémicas periodísticas.

a) la arenga: la ironía a la historia como género serio emerge con la interpretación de documentos históricos falsos acerca de los supuestos héroes Cachimbo Pérez y Botijo. El primer documento, enviado por Olimpio Pitango desde Buenos Aires, es una fotografía que está en "una hoja de papel de hilo, bastante quemada", salvada del incendio de "la famosa biblioteca del Colegio Nacional de Santiago del Estero, provocado por el canónigo" (146). Pero lo que importa no es la descripción de la fotografía sino la interpretación de la rúbrica de Cachimbo Pérez, "que será el único documento positivo revelador del modus operandi de Cachimbo al modelar sus arengas" (147). Esta rúbrica, que aparece dibujada en el texto, es interpretada según las características del discurso de la arenga, ya que reproduce el "exordio", los "argumentos" y "silogismos" de la arengas (147).

Fue precisamente el artículo incendiario de Olimpio Pitango, la arenga destinada a despertar en los monalitas el entusiasmo y el valor para que abandonaran las viejas prácticas gubernamentales, y se organizaran constitucionalmente: “¡Despierta, Monalia, de tu sueño secular! haz honor a tu nombre, levántate altiva, reivindicando tus derechos en el pasado, en el presente y en el porvenir" (85). El artículo que reproduce la oratoria de sentido patriótico de las arengas dio su fruto, pues esta "elocuencia de barricada" (86) convulsionó a todo el pueblo y desencadenó un fervor político desconocido hasta entonces.

b) la polémica es el otro género retórico satirizado a través de las diatribas cruzadas entre los dos diarios políticos, El Patriota y El Regulador. La controversia política entre estos dos diarios empieza en el cap. IV y ocupa gran parte de la novela. Mientras El Patriota apoya a Olimpio Pitango y al partido político del mismo nombre, El Regulador desprestigia todo evento que procede de dicho partido y que se relacione con Olimpio Pitango.

3. Géneroliterario: el cuento maravilloso o de hadas está representado en "La princesa Rayo de Luz", último capítulo. El esquema estructural de este cuento maravilloso corresponde a lo que Propp ${ }^{14}$ ha definido como el deseo de poseer algo, en este caso la mano de la hermosa princesa Rayo de Luz, hija de un poderoso Rey.

4. Género lírico: Holmberg utiliza este género en varias oportunidades. La mayoría son composiciones populares. Así los pensamientos autógrafos que Olimpio Pitango escribe para sus admiradoras argentinas: uno es un cuarteto de arte mayor en rima aconsonantada (107), el otro es una décima clásica de versos octosílabos (107). El tercer

\footnotetext{
${ }^{14}$ Vladimir Propp, Las raices históricas del cuento (Madrid: Editorial Fundamentos, 1987), 17 y sgtes.
} 
poema popular aparece en el cuento final, y es una octava con rima aconsonantada (189). Por último, el himno nacional que Olimpio Pitango compone titulado "El triunfo póstumo" está escrito en heptasílabos asonantados alejandrinos, con "la cesura del hemistiquio clásico" (99). La ironía aumenta cuando se sugiere que este himno permite ser cantado con la música de "Cuando Juana de Arco tocaba la corneta", con "Arroró mi niño, arroró mi amor" o con "E viva Garibaldi" (100).

La mezcla de géneros literarios con géneros extraliterarios -el histórico y el discursivo- rompe la clásica separación de los mismos, al mismo tiempo que desautoriza la preeminencia de alguno: multiplicidad de géneros canónicos con populares que persigue una carnavalización literaria.

\section{Multiplicidad IDEOLÓGICA}

La asombrosa libertad temática de la novela que incursiona en una multiplicidad de temas, refleja a Holmberg en toda su complejidad: conjunción del intelectual con el científico que aborda los más variados asuntos. Aunque muchos de estos temas se pueden rastrear en sus ensayos intelectuales y científicos, lo nuevo aquí es que Olimpio Pitango de Monalia es la primera obra de ficción de Holmberg que resume y contiene este polimorfismo ideológico.

La ideología presente permite la siguiente clasificación: 1. ciencias naturales, 2. filología, 3. cultura griega, 4. pedagogía, 5. feminismo, 6. genialidad/irracionalidad, 7. reflexión histórica.

1. Ciencias naturales. Entran en este apartado sus caras ideas acerca del transformismo y evolucionismo. Ideología que a manera de columna vertebral va sosteniendo el andamiaje de la obra.

Gran parte de esta ideología científica de Holmberg ya había aparecido en sus trabajos sobre el darwinismo que él popularizó en la Argentina. Precisamente el plan de Olimpio Pitango es la transformación de Monalia arcaica en moderna y progresista, para poder hacer frente a los deseos expansionistas de las grandes potencias.

En Monalia, país agropecuario esencialmente, se deben multiplicar los astilleros, las usinas, y construir acorazados, torpederos y submarinos, "instrumentos con que los pueblos defienden su existencia o luchan por la vida" (145). La lucha por la vida, axioma darwinista, ${ }^{15}$ "es una ley fundamental de la vida" (83). Olimpio Pitango ha intuido que, "por encima de todas las diplomacias, de todas "las fraternidades," se "levanta la ley natural del

\footnotetext{
${ }^{15}$ Según explica Holmberg, Darwin aplica en la lucha por la vida la Ley de Malthus [On Population]: "El hombre se propaga en progresión geométrica y los alimentos en progresión aritmética" (Carlos Roberto Darwin, [Buenos Aires: El Nacional, 1882] 62-63). Más adelante agrega: "los blancos, los civilizados, los cristianos, armados de remington, acabamos con los Indios, porque la Ley de Malthus está arriba de [...] opiniones individuales, [...] sea porque falte aún mucho para que la humanidad esté civilizada, sea por cualquier otra causa, no se hacen carne - y así luchando también nosotros por la vida, con buenas ideas, con buenas armas, con buenos recursos, no hacemos más que poner en juego nuestras ventajas" (Carlos Roberto Darwin, 66).
} 
hombre, de la lucha por la vida y del triunfo de los más aptos, cualesquiera que sean los instrumentos que esa lucha pueda poner en juego" (169). Lamentablemente "el espíritu de guerra" no se extinguirá "jamás en la Humanidad, género de mamíferos provisto de colmillos" (177). ${ }^{16}$

A sus conocimientos de las ciencias naturales corresponde la lista de geólogos y botánicos (158-159); la mención del Cardo de Castilla (138) —especie descubierta en la Argentina por Holmberg: ${ }^{17}$ la nómina de las aves insectívoras que son exterminadas por los cazadores (155); la descripción geográfica de la isla de Monalia — constitución geológica, hidrografia, clima, flora, fauna- con su correspondiente mapa físico (75-76).

2. Filología. A este tema corresponden las dos conferencias sobre el lenguaje dadas en Monalia. En la primera, un conferenciante monalita menciona "la teoría del lenguaje hablado antes de manifestarse en las tres formas por los filólogos" (78); alude a las tres teorías del lenguaje - la naturalista, la síquica y la de los neogramáticos- originadas por el desarrollo de las ciencias naturales, y la presencia de Darwin en el siglo XIX. En la segunda conferencia se hace referencia al sánscrito, a los dos grandes poemas épicos hindúes, el Mahabharata y el Ramayana, y a las lenguas religiosas seculares, el pracrito y palí (80), lenguas que derivan como el sánscrito del tronco ario.

3. Cultura griega. La cultura griega es otro elemento vertebrador en la obra. Las referencias abarcan las letras (Aristófanes, Homero, Esquilo, Safo, Xenofonte, Herodoto), la filosofia (Sócrates, Platón, Aristóteles), las ciencias (Arquímides), la escultura (Fidias, Praxíteles), la historia (Alejandro Magno, Alcibíades, Demóstenes, Licurgo, Solón, Pericles, Aspasia, Arístides), los deportes (Milón de Crotona), la mitología (Zeus, Apolo, Atenea, Aquiles, Teseo, Ariadna, Fedra, Pentesilea, Penélope) y la educación tanto espartana como ateniense, más de una vez modelo a seguir por los monalitas.

4. Pedagogía. Los cuarenta años de docencia de Holmberg y sus lecturas le permitieron elaborar un cuerpo de doctrinas que en la novela se materializan en la descripción de ese "paraíso terrenal" que era Monalia, y en la educación de sus niños.

La instrucción pública ha sido "la mayor preocupación" de Monalia durante los tres siglos de existencia (180). Aquí reside su "grandeza real", en esa constante inquietud "de desenvolver, desde la más tierna infancia, las aptitudes individuales de los niños” (157).

\footnotetext{
${ }^{16}$ En otra oportunidad Holmberg expresa que "La pazuniversal es una quimera" porque "el Hombre tiene la pugnacidad natural de su estirpe de colmillo" ("De Siglo a Siglo", Anales de la Sociedad Científica Argentina (julio 1901) 52, 53). En Carlos Roberto Darwin, Holmberg también puntualiza que la doctrina de Darwin podría llevar al hombre a la perfección sino fuera "indefinida por el progreso", y por los antecedentes simios del hombre (67).

${ }^{17}$ En Carlos Roberto Darwin, Holmberg informa que fue él quien descubrió la existencia del Cardo de Castilla (Cynara Cardunculus). La presencia de este cardo en el campo argentino ejemplifica "The struggle for life" de Darwin. Holmberg llamó la atención al gobierno argentino sobre la rápida propagación de este cardo nocivo para el ganado, que amenazaba desterrar las especies de cardos que comían los animales (58-63).
} 
La aptitud, se desarrollaba desde la más temprana edad en el hogar (157). En Monalia, "[h]abituados desde sus orígenes a la selección de las aptitudes" (103), para cualquier actividad era necesario ser apto, $y$ "habrían declarado loco, mal patriota y caduco al gobierno que hubiese recomendado para dirigir las actividades militares a un monalita entendido en la fabricación de vidrio solamente o a otro reconocido apto en la confeccción de versos líricos" (103). Es probable que este énfasis en la aptitud le venga a Holmberg de su conocimiento de la filosofía de Lao-Tsé y Confucio; fue éste quien proponía el cultivo de la aptitud por medio de la educación, y que sólo debía gobernar aquél que tuviera aptitud para ello.

5. Feminismo. El capítulo IX, titulado "Feminismo", reproduce el discurso del diputado Toribio Albarda acerca del papel que debe tener la mujer en el nuevo régimen constitucional. A través de ejemplos de mujeres famosas de la historia y de la mitología Catalina de Rusia, Isabel de Inglaterra, María Teresa de Austria, Isabel de Castilla, Safo, Belona, Palas Atenea y otras más- demuestra que la mujer siempre se ha destacado en cualquier actividad, ya sea política, artística o social. Aunque el discurso de Toribio Albarda propone "la intervención de la mujer en todas las tareas que corresponden a la evolución política y social de Monalia" (130), en este despliegue de funciones viriles desempeñadas por mujeres, las "reticencias escondidas en la sucesión de los ejemplos" (130) infunden sospechas.

Precisamente en el capítulo XIII, "Las mujeres de Monalia a los miembros de la Convención Constituyente", exponen que detrás de cada hombre ilustre - Humboldt, Cuvier - ha habido una madre cuyo talento le permitió descubrir y desarrollar las aptitudes del hijo. Aquí reside la superioridad de la mujer, "en la educación de la niñez y de la juventud" (161). Por lo tanto piden que los derechos electorales para la mujer, requeridos por el diputado Albarda, "no sean acompañados de la imposición militar del voto obligatorio" (161).

En consecuencia, el feminismo en Holmberg va más allá de los ejemplos de mujeres excepcionales que la Historia ofrece: la mujer tiene una misión importantísima en la nación. Holmberg continúa aquí la orientación ya iniciada en la Argentina por Alberdiy Sarmiento, ${ }^{18}$ acerca de la necesidad de que la mujer se eduque, porque de ella depende la formación de los futuros ciudadanos, la industria y la moralidad de un país.

Así lo entendió él desde muy joven, cuando se inició como profesor en la Escuela Normal de Profesoras, e introdujo el estudio de las ciencias naturales, la teoría de la evolución, los nombres de Laplace, Darwin, para desafiar a esa gente que se empeña "en que las mujeres sean solemnes ignorantes", cuya única obligación "consiste en mantener su cerebro en un estado de vacuidad seráfica" ("Discurso del Dr. Eduardo L. Holmberg",

${ }^{18}$ Véase mi estudio sobre este tema en Origenes del costumbrismo ético-social. Addison y Steele: antecedentes del artículo costumbrista español y aregentino (Miami: Ediciones Universal, 1983) 122, 144. 
Homenaje, 732). ${ }^{19}$ Producto de esta educación científica fue la Doctora Grierson, la primera médica argentina que fue su alumna en la Escuela Normal de Profesoras. ${ }^{20}$

6. La irracionalidad y la genialidad. La genialidad y el talento, enmascarados en actitudes aparentemente irracionales, aparecen más de una vez en la obra de Holmberg. ${ }^{21}$ En Olimpio Pitango de Monalia esta fusión que sirve para caracterizar a un hombre público, Olimpio Pitango de Monalia, retrotrae a los comentarios vertidos por Holmberg en su obra Sarmiento. ${ }^{22}$

Cuando Europa se entera del plan de Olimpio Pitango, lo declaran "loco o fraguando una mistificación" (96); su obra, opinan, "parece una pesadilla, verdadera creación de un lunático, y en ciertas ocasiones de un loco de remate" (97). Para Francia, Olimpio Pitango semeja Don Quijote "cuando le zumbaban al oído ráfagas de caballería" (98); y el gobierno de Monalia, ante el tumulto que su ardiente arenga ha originado, lo juzga "loco de remate" y dispone alejarlo del medio con una misión diplomática (106). Es sólo al final, después de sus actividades diplomáticas, que el gobierno comprende que "Olimpio no está loco ni lo ha estado nunca" (132); conocedor de Prometeo, —el defensor de la humanidad-es el "profeta", el "vidente" (133), que advirtió que la seguridad nacional estaba en peligro.

Seguramente la abundante bibliografia sobre la locura que proliferaba en la Argentina, Holmberg la conocía, ${ }^{23}$ pero quizás la fuente de este tema en él, haya que buscarla en el romanticismo alemán, particularmente en Hoffmann, autor que Holmberg cita constantemente, ${ }^{24}$ especialmente su relato "Councillor Krespel". ${ }^{25}$ Olimpio Pitango es otro

${ }^{19}$ Homenaje al Dr. Eduardo L. Holmberg, Revista del Centro de Estudiantes de Ingeniería, Año XVI, No 159 (setiembre 1915).

${ }^{20}$ En ocasión del Homenaje a Holmberg en 1915, cuando se retiró de la enseñanza, la doctora Grierson expresó en su discurso: "Nosotros que aprendimos el catecismo de Astete y que nuestra frágil memoria nos hizo olvidar hace rato, hemos, en cambio, tratado de poner en práctica lo que con su ejemploy palabra nos enseñó él [Holmberg]" ("Discurso de la Doctora Grierson" en Homenaje al Dr. Eduardo L. Holmberg, op. cit. 723). Es interesante la mención del catecismo de Astete del cual se hace una sátira en la novela.

${ }^{21}$ En Viaje maravilloso del Sr. Nic-Nac, el "loco del matraz"; en "El tipo más original", el extraño profesor Burbullus, políglota, que cada día de la semana habla una lengua diferente.

${ }_{22}$ Eduardo L. Holmberg, Sarmiento (Buenos Aires: Francisco A. Colombo, 1938), este estudio se publicó originariamente en El Tiempo (octubre 25, 1910, Nos. 11-18, 25).

${ }^{23}$ Pagés Larraya cita las siguientes obras y autores populares durante laépoca de Holmberg: Las neurosis de los hombres célebres de Ramos Mejía; La locura en Buenos Aires de Samuel Gache; Los manicomios de Norberto Maglioni (op. cit., 37-38). Holmberg menciona Las neurosis de los hombres célelebres de Ramos Mejía en Carlos Roberto Darwin (117).

${ }^{24}$ Además de titularse uno de sus cuentos "La pipa de Hoffmann", Holmberg comparte con Hoffmann la sátira a la sociedad de su tiempo — que esconde un horror frente a un mundo en transición— la imaginación creadora y la creación de caracteres extraños, excéntricos, locos o autómatas (Particularidades presentes en "The Sandman", "The Doubles" de Hoffmann, y en "Horacio Kalibang o Los Autómatas" de Holmberg).

${ }^{25}$ El consejero Krespel es un personaje tildado de loco por la población por sus excéntricas actitudes; es el Profesor M. quien explica su comportamiento: "There are men [...] from whom nature or some peculiar destiny has removed the cover beneath which we hide our own madness. They are like thinskinned insects whose visible play of muscles seem to make them deformed, though in fact, everything 
Krespel, según las palabras del jefe de gobierno, Claudio Moloso, que "[p]ara realizar [su] gran concepto [ha] gesticulado como un violinista" (163), símbolo que se intensifica cuando más adelante agrega Moloso que "la seguridad de la Patria exigía que continuara Krespel gesticulando en su violín de Cremona." (164).

No por nada este personaje Krespel es recordado por Holmberg cuando escribe sobre Sarmiento, para justificar la expresión de "morisquetas" irracionales para la mayoría, ${ }^{26}$ pero que resultan un acto de catarsis interior:

'En el fondo del alma de todo hombre, por serio y grave que sea' — contesta Krespel— 'hay una morisqueta escondida. Si no se suelta al aire, como yo lo hago, se convierte, por extrañas metamorfosis, en semillero de maldades. Ella es origen de calumnias, maledicencias e injurias, todo lo cual no se aviene con mi carácter' (Sarmiento, 50).

Es por esto que el "loco Sarmiento" —como lo llamaban despectivamente-y Olimpio Pitango serían ejemplos de seres en los que la genialidad produce morisquetas aparentemente irracionales.

La clave de la personalidad de Sarmiento, tal cual la delinea Holmberg en su estudio Sarmiento, permite extraer las siguientes semejanzas con Olimpio Pitango: ambos son grandes oradores y diplomáticos, hombres públicos en conflicto con su medio que asumen la labor de organizar constitucionalmente sus países. Sarmiento en 1800, Olimpio Pitango en 1900 tienen sentido porque: "En las diversas tonalidades de la cultura humana, cada una de ellas tendrá con el tiempo, entre nosotros los Argentinos, un Sarmiento propio" (Sarmiento, 47). Parafraseando a Renan, Holmberg agrega que "muchas veces se confunde el loco con el hombre inspirado; pero el loco no deja en pos de sí nada estable. El extravío de la razón no ha tenido hasta ahora ninguna influencia en la marcha del género humano" (Sarmiento, 41). Esta confusión entre el loco y el hombre inspirado resulta por no haberse advertido que la "individualidad humana sólo proyecta una imagen virtual" de la vida (Sarmiento, 15).

Lo que está representando Holmberg, tanto en su descripción de Sarmiento, como en la caracterización de Olimpio Pitango, es - como él mismo lo expresa-la fusión de genio y talento al "servicio de doctrinas políticas o sociales" (Sarmiento, 39), que despiertan "en [el] espíritu todas las incongruencias de un loco y todas las fulguraciones de un genio" (Sarmiento, 42). Así, cuando Olimpio Pitango regresa a Monalia, después de su misión diplomática, le explica al gobierno que su reforma política y social, consecuencia de "una larga premeditación", le significó en un primer momento un dilema:

soon returns to its normal shape again [...] Krespel expresses bitter scorn in mad gestures and irrational leaps, even as does the spirit which is embedded in all earthly activity". ("Councillor Krespel", Selected Writings of E. T.A. Hoffmann. vol. I. Ed. y trad. Leonard J. Kent y Elizabeth C. Knight [Chicago-London: The University of Chicago Press, 1969] 180).

26 " [L] $]$ os que hemos tenido oportunidad de examinar sus manuscritos de periodista, [las contribuciones de Sarmiento a la prensa argentina y chilena] hemos podido encontrar más de un tic simbolizado por un rasgo intempestivo de pluma o por una interjección demasiado profana" (Sarmiento, 34-35). 
Aquel dilema se formulaba de este modo: $O$ expongo en forma seria y grave los fundamentos de la reforma necesaria ... o bien expongo esos fundamentos en una forma fantástica y descabellada para una minoría seria y grave que me considerará loco de remate y me dejará en paz, pero imponente y necesaria para una mayoría abrumadora, y en tal caso hay probabilidades de triunfo y entonces mi obra puede ser fecunda (Olimpio Pitango de Monalia, 164).

Implícito está aquí el concepto de que las masas reaccionan más fácilmente ante actitudes irracionales, porque no piensan - tema ya desarrollado en la Argentina por Alberdi- ${ }^{27}$ Holmberg expresa también en Sarmiento:

Y cuando el genio y el talento se funden por extraño consorcio, tal cual sucede en Sarmiento, y esa fusión se pone al servicio de doctrinas políticas o sociales, el mundo interno que encierra aquel caudal es como la espada flamígera del arcángel, que podrá deslumbrar á las turbas, pero no a los que flotan en la región de los iguales superiores (Sarmiento, 39).

Quizás Holmberg esté dando la clave de su quehacer cuando confiesa que después de haber leído las obras de Sarmiento (especialmente Facundo y sus artículos periodísticos), y de haber escuchado algunas de sus conferencias, advierte que la caracterización de Sarmiento podría figurar "en alguna parte como personaje de novela" y, "es evidente que habría podido constituir una personalidad más subjetiva que desenvuelta en la circunstancialidad de la trama" (Sarmiento, 24).

7. Reflexión histórica. Este aspecto que lo acerca a Sarmiento en más de una ocasión, especialmente en sus ideas acerca de la herencia española y en el análisis de los cánceres de las naciones sudamericanas, encaja perfectamente con la figura del intelectual que reflexiona más de una vez acerca de su país e Hispanoamérica. ${ }^{28}$

Es el discurso testimonial de Olimpio Pitango, ministro plenipotenciario en Sud América, el que va descubriendo una realidad caótica. Aunque Monalia, Uruguay y la Argentina tienen el mismo origen e idioma, la misma sangre, las mismas necesidades, Monalia difiere de ellas porque "henchida de civilización [...] no surge de la barbarie colonial, de la ignorancia, del fanatismo, del atraso en que aquellas dormían" (165). Agudamente realiza la radiografía de los "cánceres" sudamericanos que impidieron el ejercicio de la democracia:

${ }^{27}$ El concepto del pueblo-masa, sin criterio propio, ya aparece en el periódico La Moda (1837) de Alberdi. Analizado en mi libro Orígenes del costumbrismo ético-social (121).

${ }^{28}$ En mi estudio sobre Olimpio Pitango de Monalia que introduce la edición de la novela me explayo sobre un aspecto soslayado por la crítica: la estrecha vinculación entre Sarmiento y Holmberg, dos intelectuales en oposición con el medio que hay que reformar. Mientras Sarmiento polémicamente sostuvo la defensa de la modemización de la Argentina, Holmberg, que continúa la misión progresista de Sarmiento, agrega la difusión de la ciencia fundada en el estudio de la naturaleza, para poder combatir la ignorancia que es el arma de la tiranía, y para difundir el conocimiento del suelo argentino. Ambas funciones de estos intelectuales fueron didácticas: la de Sarmiento, didáctico-política; la de Holmberg, didáctico-científica. 
[L]as naciones hispanoamericanas eran víctimas [...] del espíritu añejo de su origen, con leyes civiles y militares hediondas de Inquisición y de Siete Partidas, tufo de horcas y de conventos, ínfulas de republicanos que hablaban de libertad y democracia mientras hacían punterías a blasones apócrifos [...] señores feudales civilizados y bruñidos en los grandes centros, y asesinos inmundos de cepo y de látigo en los tugurios solariegos adquiridos por la usurpación a los débiles; corazones corrompidos por el ejercicio de una autoridad secular ejercida sobre almas primitivas a las que no habían dado en tanto tiempo otra luz que la de los candiles conservándolos bajo la influencia de un terror perpetuo con el nombre de religión (170).

Es importante rastrear las concomitancias de esta ideología con los artículos periodísticos de Sarmiento, para quien el origen común de los países sudamericanos es también la causa de todos los males:

Hijos de unos mismos padres, mal educados, con hábitos viciosos que engendró la política de un siglo oscuro, y con las mismas dificultades en la transición, no es extraño que en todas partes suceda lo mismo y que aquí y acullá un observador halle los mismos defectos, encontrando las causas en origen idéntico ("La comedia de la libertad", El Mercurio, nov. 14, 1841, Obras completas, vol. IX, Instituciones Sudamericanas [Buenos Aires: Imprenta y Litografia Mariano Moreno, 1896] 43).

Estos antecedentes, para Olimpio Pitango, explican el desarrollo político de la Argentina. "[D]espués del régimen colonial absurdo y tiránico" (Olimpio Pitango, 104), no pudo educar a las masas por el surgimiento de la anarquía militar, que trajo como corolario la dictadura de Rosas. Como no se había enseñado lo que era la fraternidad y la igualdad, el concepto vago de patria "olía a terruño y la independencia había pasado a ser una época histórica y nada más” (Olimpio Pitango, 172).

En El Nacional Sarmiento ya había señalado la falta de preparación de los pueblos americanos para vivir procesos democráticos:

Al ver la serie de sucesos desgraciados, las tentativas malogradas y la falta de pericia de los pueblos americanos para organizarse de un modo permanente y estable, han creído muchos que la Revolución se inició a deshora y cuando los pueblos no estaban preparados para la libertad, como si alguna vez el despotismo colonial, y el despotismo español sobre todo, fuese parte á preparar otra cosa que retroceso y envilecimiento ("Política americana", El Nacional, abr. 14, 1841, Obras, Vol. IX, 16-17).

En el desarrollo político de un siglo, señala Olimpio Pitango, la Argentina había experimentado todas "las locuras de los ensayos de la democracia" (Olimpio Pitango, 133): ${ }^{29}$ la constitución, que no se había reformado en medio siglo aunque se violaba con

\footnotetext{
${ }^{29}$ Hay una especie de collage en el manuscrito formado con recortes de periódicos, que confirman la reflexión en el texto sobre la incompetencia de las naciones sudamericanas para vivir procesos democráticos. En el reverso de la página 11 del capítulo II del manuscrito, Holmberg ha pegado dos recortes de periódicos. El primero lleva como título: "1811. Revolución del Paraguay", donde se informa que el movimiento emancipador del Paraguay fue iniciado por la presencia de Belgrano, que
} 
frecuencia en la práctica, la libertad de cultos, "aunque la religión del estado permit[ía] a los gobernantes levantar una iglesia [católica] donde [faltaba] una escuela" (Olimpio Pitango, 172), la reciente ley sobre el sufragio secreto y obligatorio de Saénz Peña, ${ }^{30}$ originada ante la anarquía política que había perpetuado el fraude electoral (Olimpio Pitango, 105).

Este fracaso del sistema institucional puesto en funcionamiento por los liberales, Sarmiento lo entendió perfectamente:

queríamos hacer avanzar a la América en el camino del progreso i de la civilización europea. Por desgracia ha sucedido lo contrario" "Al Señor H. Southern, encargado de negocios de S.M.B. Cerca del gobierno de Buenos Aires" Crónica, enero 20 1850, Obras, vol, VI, Política argentina [Paris: Berlin Hnos., 1909] 288).

Y también:

Las instituciones liberales sucumben en América, como plantas exóticas arrojadas en suelo ingrato y estéril ... Es sin duda desconsolador el cuadro que el mundo civilizado presenta hoi. Vése la humanidad echada en una vía fatal, empujada hacia adelante por antecedentes que no la dejan pararse un momento ("De la Revolución Arjentina, El Progreso, enero 11 1843, Obras, vol. VI, 93).

En Olimpio Pitango, las deficiencias de este sistema se complementan con el análisis de la realidad socio-económica argentina de principios del siglo (1912-1913). ${ }^{31}$ Los males que sufre la Argentina actual, la ausencia de los valores éticos de la sociedad, la excesiva burocracia y la crisis económica, ya fueron pulsados en el discurso "sociológico" (152) de Olimpio Pitango.

inspiró el sentimiento de libertad. La revolución libertadora fue el 14 de mayo de 1811 y cuatro días más tarde, el 15 de mayo, la declaración de la Independencia. Este recorte pertenece a la sección de "Efemérides" del periódico La Razón (14 de mayo de 1912, p 13). El segundo recorte titulado, "Recibimiento del ejército. Asunción Mayo 14", alude a que el recibimiento del ejército vencedor de la actual Revolución en 1912, que depuso al presidente, el coronel Jara, coincide con el aniversario del movimiento emancipador. En este recorte Holmberg ha escrito al costado: "La Razón. Martes Mayo 14 de 1912". Efectivamente este recorte se publicó también en el mismo periódico en la página 9, y es un fragmento de un artículo más extenso titulado, "Sucesos Paraguayos. La última jornada de la revolución. El ejército vencedor de Asunción" que comenta los últimos acontecimientos de la Revolución. Ambos recortes testimonian cómo una nación sudamericana, Paraguay, al cabo de un siglo, 1811-1912, todavía sigue viviendo procesos revolucionarios de inestabilidad institucional.

${ }^{30}$ Alude a la ley de Roque Saénz Peña sobre el voto secreto y obligatorio, aprobada en 1912 durante su presidencia (1910-1914). Por primera vez en la historia argentina, en 1916 se elige libremente según esta ley al presidente Hipólito Irigoyen del Partido Radical. Los radicales se habían abstenido en el pasado de votar debido a que las elecciones estaban controladas por la aristocracia terrateniente (George Pendle, Argentina [London: Oxford University Press, 1963], 67-69).

${ }^{31}$ Mucho más tarde, José Luis Romero reflexionará sobre lo mismo: "The institutional system established and put into effect by the liberals little by little ceased to be adequate, being more advanced than actual conditions in some ways but deficient in many others (José Luis Romero, A History of Argentine Political Thought, trad. Thomas F. McGann [Stanford CA: Stanford Univesity Press, 1963], 165). 
A Olimpio Pitango le causa malestar "cierta superficialidad" en el carácter de los porteños que toman a risa cuestiones graves. En los negocios hablan de una diferencia de "2 o 3 millones ... como si se tratara de centavos" (152), pero como "se ganan el dinero con tanta facilidad" hay muchos potentados que hace unos años "carecían de zapatos" (152). Asombra la cantidad de intelectuales y "el arte soberano de algunos brutos para codearse con desenvoltura entre esos intelectuales" (151). Con respecto a la aptitud, "base de la estructura física, intelectual, moral y social de Monalia" se desconoce en la Argentina, "que cuando necesitan un diplomático nombran un bailarín" (143), ${ }^{32}$ así "hay lugar para todos sin distinción de raza ni de aptitud" (143).

El gobierno que acaba de gastar 200 millones en la celebración del centenario de la Independencia argentina (1910), no habla de crisis económica, sino del abaratamiento de la vida. Si la carne vacuna sufre un impuesto de $1 \%$ en el costo, el precio de venta de la misma sube un 50\%, este "robo" al consumidor es justificado como inflación (153). ${ }^{33}$ La carencia de frutas y de verduras se debe a que "los acaparadores la[s] compran por mayor" para surtir los hoteles o exportarlas, y cuando finalmente el consumidor puede adquirir algo de lo que haya quedado, lo paga con un aumento del $900 \%$ por "el número de intermediarios que separa al consumidor del productor" (154). Los abusos de la libertad de comercio llevan a la especulación y la deshonestidad, así el caso de un genovés enriquecido con la fabricación de vino falso (156). ${ }^{34}$

El escalpelo de la crítica minuciosa ausculta todas las deficiencias de la realidad social argentina: la carestía de la carne por la matanza indiscriminada de vacunos, la falta de caminos en el campo, la insólita presencia de campos de pastoreos para criar vacas lecheras en los alrededores de la ciudad, la ausencia de las yerbas aromáticas europeas en las comidas argentinas, la proliferación de las plagas de insectos debida a la caza de las aves insectívoras (153).

\footnotetext{
${ }^{32}$ Una observación similar aparece en Beaumarchais: "il fallait un calculateur, ce fut un danseur qui l'obtint" (Le Mariage de Figaro en Studies on Voltaire and the Eighteenth Century. vol. LXIIIT, Besterman Ed. (Geneve: Institut et Musee Voltaire, Les Delicies, 1968), 437; "Et si je deviens ministre, qu'est-ce qu'on dira? - Que vous etes le plus beau danseur de tous les conseils du roi" (Notes et réflexions [Paris: Hachette, 1961] 76).

${ }^{33} \mathrm{La}$ obra testimonia un aspecto de la vida social que aparece escasamente documentada en las obras específicas. José Panettieri en Argentina: historia de un país periférico. 1860-1914 (Buenos Aires: Centro Editor de América Latina, 1986), alude a las deficiencias de información sobre este aspecto durante los años 1899-1903, pero confirma que efectivamente hubo carestía en Buenos Aires y da algunos guarismos: "En cuanto al aumento de los artículos de consumo [...] pueden efectuarse, aproximadamente algunas comparaciones. La carne de vaca, [...] cuyo precio en 1904 era, según calidad, de 0,18 a 0,40 peso el kilogramo, costaba, en igual relación, 0,25 a 0,80 en 1911 [...] Las papas, que costaban 0,05 a 0,10 pesos, habían elevado su precio a 0,20 " (192).

${ }^{34}$ Esta quiebra de laética por el inmigrante en la Argentina sería testimoniada más tarde por la sociología: "The immigrant had simultaneously broken his ties with his birthplace and abandoned the system of norms and principles that had regulated his conduct. Both as a citizen and as an ethical being, the immigrant was a person uprooted, to whom his adopted country, because of its scanty population and level of development, could not offer an explicit, fixed, social and moral structure to replace that of the land he had forsaken" (José Luis Romero, op. cit. 174).
} 
Otro cáncer detectado en la sociedad argentina es la burocracia, oficinas estatales llenas de empleados con "aires de perros rabiosos", cuyos asuntos más importantes son los concernientes al té o al café. Administraciones papeleras que se preocupan más por la forma de un expediente, que por el contenido; un expediente puede pasar por veinte oficinas que desconocen el asunto, hasta que finalmente lo olvidan.

La Argentina vivía un exultante progreso y no tenía plena conciencia de su futura crisis. Buenos Aires era según Olimpio Pitango "un maravilloso Gargantúa" (156). Visión que reproducía prematuramente un mundo dado vuelta en los años en que la Argentina figuraba entre los países de mayor desarrollo económico. ${ }^{35}$ La novela cobra así gran actualidad pues las denuncias emitidas en 1915 detectan los males de la Argentina actual: la inestabilidad económica, la burocracia, la ausencia de valores éticos en una sociedad no preparada históricamente para vivir procesos democráticos.

Olimpio Pitango de Monalia es la obra totalizadora de la actividad creadora de Eduardo L. Holmberg, ya que al participar de toda su vida, es Holmberg en toda su complejidad, en todos sus tiempos. La novela es un temprano ejemplo de la vanguardia, de la textualización de la modernidad hispanoamericana, no sólo por la visión carnavalesca del mundo representado - las situaciones extremas y ridículas, las disparatadas interpretaciones paleográficas, la invención de héroes y documentos históricos- sino por la pluralidad de discursos opuestos, la multiplicidad de géneros y la conciencia de una diversidad de voces y de culturas en Hispanoamérica. Olimpio Pitango de Monalia al ejemplificar el legado modernista en la modernidad, tiende el puente entre el modernismo $0^{36} \mathrm{y}$ la vanguardia, tema de indagación de la crítica actual sobre el modernismo.

${ }^{35}$ Levene describe la atmósfera de exultante optimismo previa a la crisis de 1930: "Tranquilidad institucional; avances en la perfección de las prácticas de la democracia política; prosperidad económica y financiera; ganados y praderas con trazos definitorios de ampulosa riqueza; ... Sí, el país avanzaba con tal soltura que no cabía dudar de su futuro" (Gustavo Levene, Historia Argentina t. III [Buenos Aires: Editorial Campano, 1964] 234).

${ }^{36}$ En El modernismo argentino incógnito en "La Ondina del Plata y Revista literaria (1875-1880)" (Bogotá: Instituto Caro y Cuervo, 1993), donde estudio los orígenes del modernismo en la Argentina, analizo a Holmberg como a uno de los primeros cultivadores de esta nueva literatura. 